\title{
Vigilancia, represión y disciplina laboral en la Sociedad Explotadora de Tierra del Fuego (1910-1919)
}

Surveillance, repression and labor discipline in the Sociedad Explotadora of Tierra del Fuego

(1910-1919)

Nicolás Gómez Baeza*

Resumen: El presente artículo busca profundizar el análisis de la violencia ejecutada hacia trabajadores durante la década de 1910, en los espacios de la Sociedad Explotadora de Tierra del Fuego, la compañía ganadera ovina más importante del Territorio de Magallanes del período. Tras la revisión de fuentes de diversa índole, se plantea que dichas violencias, lejos de ser excepcionalidades, fueron escaladas que respondieron a objetivos de disciplinamiento de la mano de obra y mantención de poder patronal frente a la agencia desarrollada desde la clase obrera local, y contribuyendo a la configuración de escenarios de conflicto.

Palabras clave: Disciplinamiento laboral, Historia empresarial, Historia del trabajo, Violencia

\begin{abstract}
This paper seeks to deepen the analysis of violence executed against workers during the decade of 1910, in the spaces of the "Sociedad Explotadora de Tierra del Fuego", the most important sheep farming company at that period on the Territory of Magallanes. After reviewing different sources, it is proposed that such violence, far from being exceptional, were escalations that responded to objectives of labour discipline and maintenance of employer power, facing the agency developed from the local working class, and contributing to the configuration of conflict scenarios.
\end{abstract}

Keywords: Labour Discipline, Bussines History, Labour History, Violence

Recibido: 5 agosto 2018 Aceptado: 3 octubre 2018

\section{Introducción}

En los últimos días de enero de 1919 se desarrolló una huelga en el Frigorífico de Puerto Bories, en el distrito de Última Esperanza del entonces Territorio de Magallanes, Patagonia chilena, derivando en fatales enfrentamientos entre operarios del establecimiento y sus autoridades, administradores y vigilancia estatal, que se concentraba en la zona, desencadenando a posterioridad una reacción represiva comandada por batallones del ejército chileno y argentino. Estos acontecimientos conocidos también como los "Sucesos de Natales" o la "Comuna de Natales", se desarrollaron en un establecimiento de la Sociedad

\footnotetext{
* Chileno. Magíster en Historia, mención Historia de Chile. Universidad de Santiago de Chile. Correo electrónico: ngomezbaeza@gmail.com
} 
Explotadora de Tierra del Fuego (desde ahora SETF), la empresa ganadera más grande de la Patagonia y Tierra del Fuego occidentales, en soberanía territorial chilena. Fue un episodio que se ha considerado como una coyuntura en la conflictividad de clases, la represión estatal-ganadera y la violencia en el Territorio de Magallanes y puntualmente en la también llamada "Explotadora".

Si bien este artículo no se plantea volver a relatar este suceso específico, como ya lo han hecho notablemente otros autores ${ }^{1}$, es inevitable re-pensar la violencia ejercida por la SETF, a la luz del primer centenario de la huelga de Puerto Bories (1919-2019). Por ello es que este trabajo se propone analizar las prácticas administrativas de la también llamada "Explotadora" en el uso de mecanismos violentos hacia los trabajadores, anteriormente al hito mencionado, a lo largo de la década de 1910. Aquel es el objetivo central de este trabajo, intentando responder qué características tuvo el ejercicio de la violencia por parte de la más grande compañía ganadera de la Patagonia chilena.

El ejercicio de la violencia desde la SETF no fue una excepcionalidad que se remitió a lo acontecido en Puerto Bories en 1919, sino una constante que se desarrolló al menos durante toda la década de 1910 como práctica recurrente y, muchas veces, sistemática (aunque no necesariamente homogénea), respondiendo a objetivos de disciplinamiento de la mano de obra, evidenciando un carácter disuasivo y represivo del control social. Específicamente, las prácticas violentas fueron generadas directamente desde las administraciones de la "Explotadora", tanto desde el alto mando de los Administradores Generales como desde las administraciones locales de establecimientos productivos de la compañía (estancias y el mismo frigorífico Bories). Pero también mediante las relaciones de cooperación que dichas autoridades tenían con la autoridad civil (gobernación) y de orden (militar o policial). Tanto la vigilancia como la represión directa -violencia agresiva- en episodios de confrontación o en la misma cotidianeidad de los espacios productivos, se pueden identificar, de esta manera, como parte de la cultura de administración ganadera de la SETF, y desarrollada conjuntamente con los agentes del poder político del Territorio.

El presente trabajo busca ser parte de las producciones en historia social de las culturas empresariales y de las relaciones laborales a escala regional. ${ }^{2}$ Dentro del contexto de la producción historiográfica local, el presente artículo se sitúa entre dos dimensiones. La primera es la de una línea ya desarrollada que ha evidenciado el escenario de violencia en Magallanes y el espacio patagónico-fueguino binacional argentino-chileno a comienzos del siglo veinte. Existen estudios clásicos y contemporáneos que han relatado hechos de violencia como parte de conflictos huelguísticos obreros que terminaron en actos represivos, existiendo incluso análisis más recientes sobre el ejercicio de la violencia monopólica estatal en Argentina y Chile. ${ }^{3}$ A su vez, en la última década, se han publicado trabajos sobre el comportamiento de las elites políticas y económicas a finales del siglo XIX y comienzos del siglo XX, incluyendo análisis de prácticas de corrupción y clientelismo en la constitución de las soberanías desde los Estados argentino y chileno. ${ }^{4}$ Estos trabajos entregan la oportunidad para la profundización de miradas respecto a la comprensión de prácticas de quienes detentaban el poder de decisión dentro de los espacios de la producción ganadera, como fue la violencia ejercida hacia los trabajadores. Es ahí donde,

\footnotetext{
1 Para un relato detallado de dichos acontecimientos, se sugiere: Ramón Arriagada, La Rebelión de los Tirapiedras, Punta Arenas, Ediciones Universidad de Magallanes, 2010.

${ }^{2}$ Hablar de culturas empresariales, y no de una sola, da cuenta de la necesidad de establecer diferencias y particularidades. Dicha idea se considera a partir de comentarios editoriales.

3 Sobre episodios específicos donde se destacan tanto episodios represivos como la capacidad organizativa del movimiento obrero en Magallanes durante la década de 1910, destacan: Ramón Arriagada, op. cit.; Carlos Vega Delgado, La Masacre de la Federación Obrera de Magallanes, Punta Arenas, Editorial Ateli, 2 Edición, 2002; Carlos Vega Delgado, 1915 La Primera Gran Huelga Natalina, Punta Arenas, Impresos Ateli, 2009. Un reciente estudio sobre la violencia estatal en Argentina y Chile se puede encontrar en: Alberto Harambour, "Monopolizar la violencia en una frontera colonial. Polici $\square$ as y militares en Patagonia austral (Argentina y Chile, 1870-1922)", Quinto Sol, Vol. 20, No 1, enero-abril 2016, 1-27.

${ }^{4}$ Ernesto Bohoslavsky, El Complot Patagónico: Nación, Conspiracionismo y Violencia en el sur de Argentina y Chile, Siglos XIX y XX, Buenos Aires, Prometeo Editorial, 2009; Alberto Harambour, "Soberanía y Corrupción. La construcción del Estado y la propiedad en Patagonia austral”, Historia, No 50, Vol II, julio-diciembre 2017, 555-596.
} 
justamente, este artículo busca contribuir, recopilando nuevos antecedentes, en complemento con datos ya expuestos, respecto de las autoridades de la SETF. ${ }^{5}$

La segunda dimensión desde la que se posiciona este artículo, es en la necesidad más general de discutir con ideas de una historiografia regional, que han enfatizando mayormente en procesos de modernización protagonizados por las elites políticas y económicas formadas al alero del capital ganadero y comercial. La producción historiográfica puede resumirse en trabajos que han construido un relato desde la misma institucionalidad empresarial o bien desde miradas afines hacia su obra modernizadora. ${ }^{6}$ Un ejemplo de esta mirada es la afirmación con la que Mateo Martinic, considerado tradicionalmente como referente de la historiografía regional, resume el carácter de las relaciones laborales de la compañía: "Así $\square$, con aspectos de dulce y de agraz, se dio la vida laboral de la Sociedad Explotadora de Tierra del Fuego y acabo $\square$ por imponerse la aceptación de su existencia como una cosa buena y necesaria para la inmensa mayoría de la gente, en especial entre la población de U $\square$ ltima Esperanza (...).” . Si bien el autor dedica dos páginas del citado artículo a hablar de las malas condiciones de vida y laborales de la clase obrera de la empresa o en las reivindicaciones de la Federación Obrera de Magallanes (FOM) en sus primeros años de funcionamiento (el "agraz"), no menciona la violencia como parte del repertorio de la administración. Al no considerar el carácter conflictivo y los mecanismos de ejercicio o disputa del poder como parte constitutiva de las dinámicas relacionales de los espacios ganaderos, se vuelve una visión conciliadora que, como refleja la cita, enfatiza en una labor de aporte al progreso por parte de la compañía ("el dulce", que abarca las demás páginas del artículo). Se busca, entonces, profundizar en la comprensión del devenir de la SETF desde su rol ejercido dentro de escenarios de conflictividad en la década de 1910.

La manera en que se perciba la violencia y la intensidad en que se ejerció depende de múltiples factores entre los que se encuentran principalmente el contexto sociocultural de los individuos. Es la historia de cada sujeto y su contexto cultural influyen en la naturalidad del pensar, sentir y actuar violentamente, no siendo posible entender la violencia solamente como eventos o coyunturas. ${ }^{8} \mathrm{Al}$ ser histórica, la violencia no es una acción unidireccional, sino que relacional, considerando la necesaria construcción social a través de la interacción de los sujetos. El conflicto se plantea como "condición necesaria, pero no suficiente" de la violencia, considerando tanto los condicionamientos estructurales como episodios coyunturales donde grupos rivales se confrontan. ${ }^{9}$

En concordancia con lo planteado por Corsi y Peyrú, la violencia está conformada por conductas con objetivo de obtener el control y la dominación sobre otras personas, mediante el uso de operaciones que ocasionan daño físico, psicológico o de otra índole. ${ }^{10}$ La conducta violenta, “(...) entendida como el uso de la fuerza para la resolución de conflictos interpersonales, se hace posible en un contexto de desequilibrio de poder, permanente o momentáneo."11 Aquello es coherente con la noción de

\footnotetext{
${ }^{5}$ Un trabajo sobre la "Explotadora" donde se han recopilado antecedentes referentes a la construcción de la dominación del espacio productivo estanciero, incluyendo prácticas de control obrero como parte de los mecanismos de construcción de la producción: Joaquín Bascopé, "Pasajeros del Poder Propietario. La Sociedad Explotadora Tierra del Fuego y la Biopolítica Estanciera (1890-1920)", Magallania, Vol 36, 2008, 19-44.

${ }_{6}^{6}$ Ejemplos clásicos y contemporáneos son: Fernando Durán, Sociedad Explotadora de Tierra del Fuego, 1893-1943, Santiago, Imprenta y Litografía Universo, 1943; Mateo Martinic, "Recordando a un Imperio Pastoril: La Sociedad Explotadora Tierra del Fuego (1893-1973)", Magallania, Vol. 39(1), 2011, 5-32.

7 Mateo Martinic, "Recordando a un Imperio Pastoril: La Sociedad Explotadora Tierra del Fuego (1893-1973)", op. cit., P. 23

8 Jorge Corsi y Graciela Peyrú, Violencias Sociales, Buenos Aires, Ariel, 2003, P. 59

${ }_{9}$ Eduardo González Calleja, La violencia en la poli $\square$ tica. Perspectivas ted $\square$ ricas sobre el empleo deliberado de la fuerza en los conflictos de poder, Madrid, Consejo Superior de Investigaciones Cienti $\square$ ficas (CSIC), 2002, P. 61. A su vez, Adriana González Gil plantea que “(...)rasgo característico que tipifica una forma de conflicto en un contexto sociopolítico bistóricamente determinado." Y si bien no se concuerda necesariamente con un determinismo unidireccional que reste agencia a los sujetos históricos, la influencia de los contextos socioculturales para la generación de conflicto se consideran igualmente necesarios para el desarrollo de la violencia en contextos particulares. Adriana González Gil, "Acción colectiva en contextos de violencia prolongada”, Estudios Politicos, Medellín, N²9, julio-diciembre 2006, P. 37.

10 Jorge Corsy y Graciela Peyrú, op. cit., P. 40

${ }^{11}$ Ibid. Pp. 29
} 
disciplinamiento de la mano de obra como acción de repertorio y deliberada, siendo la disciplina del trabajador "condición esencial" para la producción, "históricamente determinada del control patronal sobre el proceso del trabajo"12. Cuando se observa el ejercicio violencia patronal situada en dichos contextos históricos de expansión capitalista, es posible considerarla como parte de mecanismos de disciplinamiento laboral. ${ }^{13}$

Es así como los repertorios de la disciplina de la mano de obra, como las acciones de violencia, deben comprenderse tanto desde el ejercicio del poder como desde las recepciones y, muchas veces, las resistencias. ${ }^{14}$ Desde esa perspectiva, la metodología utilizada se basa principalmente en la historia cultural, y específicamente considerando la producción de textos donde distintos actores que se vieron envueltos, desde la exposición de propias experiencias y visiones, en las acciones de violencia de la "Explotadora". Las fuentes utilizadas provienen tanto de documentos oficiales del mundo empresarial, como también de raigambre obrera, especialmente periódicos ampliamente conocidos para el estudio de historias del período, como "El Trabajo" y "El Socialista", además de una publicación contemporánea de la época de Gregorio Iriarte, quien fuera simpatizante de la FOM y periodista ligado al diario "El Magallanes". Es así como, si bien no es objeto de estudio de este trabajo el indagar sobre el poder efectivo que el movimiento obrero magallánico desplegó en su relación con la clase empresarial local (debido a que ya ha quedado en evidencia en trabajos referidos), es necesario abordar el desarrollo de sus visiones sobre las violencias ejercidas por la SETF en tanto receptores o testigos en lo cotidiano y en episodios como las mismas huelgas.

Complementariamente se ha considerado otra prensa masiva del contexto, además de fuentes gubernamentales pertinentes, provenientes del Archivo Nacional Histórico de la Biblioteca Nacional de Santiago de Chile, específicamente del fondo de Gobernación de Magallanes. Complementariamente, cabe destacar que existen trabajos de autores mencionados a quienes también ha cabido hacer referencia, dando cuenta del importante desarrollo de estudios desde la disciplina histórica en torno a episodios de violencia social magallánica.

\section{El escenario de poder de la Sociedad Explotadora de Tierra del Fuego}

En el Territorio de Magallanes los orígenes de la actividad ganadera se remontan oficialmente a las gestiones estatales en 1876, cuando bajo la administración del gobernador local Diego Duble Almeyda se obtuvieron las primeras trescientas ovejas desde las Islas Malvinas, informándose previamente de las ventajas de aquel modelo de producción británico. Fue, sin dudas, el vínculo con el espacio colonial británico lo que más potenció el negocio. ${ }^{15}$ Los inicios de la SETF no fueron muy diferentes, comenzando con negociaciones entre el navegante portugués José Noguiera y el presidente José Manuel Balmaceda desde donde se conceden terrenos en Tierra del Fuego, y consolidándose con Mauricio Braun quien, al serle cedida la concesión tras la muerte del portugués, fundó la compañía con aporte de los capitales británicos de Duncan Fox Company, y su representante en Chile, Peter McClelland. ${ }^{16}$ Desde aquel

12 Jean Paul De Gaudemar, El Orden y la Producción. Nacimiento y formas de disicplina en las fábricas, Madrid, Edtorial Trotta, 1991, P. 45.

13 Un trabajo reciente que considera una matriz de análisis similar, se refiere a lo sucedido en la cuenca carbonífera de Lota, también en la década de 1910: Oscar Peñafiel, "Violencia patronal, mayordomos, policías: Paternalismo patriarcal en la cuenca carbonífera. Lota, 1910-1920”, Revista Tiempo Histórico, Año 6, Nº11, julio-diciembre 2015, P. 42.

${ }^{14}$ Jean Paul De Gaudemar, op. cit., P. 50. Sobre la capacidad creativa y la resistencia desde abajo, ver: Tomás Mantecón, "Formas de Disciplinamiento Social. Perspectivas históricas”, Revista de Historia Social y de las Mentalidades, Vol 14, No2, 2010 , P. 291.

15 Mateo Martinic. "El Ordenamiento Rural en Magallanes, 1894-1973: La dirección y el manejo de las grandes estancias”, Vida Rural en Chile Durante el Siglo XIX, Santiago, Academia Chilena de la Historia, 2001, Pp. 175-176. Para mayor detalle sobre el caso específico de "Malvinas" y la incidencia ganadera en la región patagónica, ver: Alberto Harambour, "Sheep Sovereignties: The Colonization of the Falkland Islands/Malvinas, Patagonia, and Tierra del Fuego, 1830s-1910s", Oxford Research Encyclopedia of Latin American History, sept 2016, 1-25.

16 Mateo Martinic, "Recordando un Imperio Pastoril...", op. cit., Pp. 6-9; Alberto Harambour, "Borderland Sovereignties. 
momento, el crecimiento y la influencia de la "Explotadora" traspasó los límites de la isla, expandiendo su adquisición de tierras mediante nuevas concesiones o compras a productores menores hacia la Patagonia sur en Argentina y Chile, destacándose el funcionamiento de una gran cantidad de estancias las dos primeras fueron Caleta Josefina (1893) y San Sebastián (1894)- y frigoríficos desde 1913, siendo el primero y emblemático el de Puerto Bories. ${ }^{17}$ Solamente personas de origen británico eran nombrados administradores o "managers" en la compañía, y en algunos casos, los directivos de la compañía preferían trabajadores también de cargos medios provenientes de Gran Bretaña y su imperio. ${ }^{18}$

Por otro lado, sus trabajadores eran mayoritariamente temporales, como se indicaba en la documentación oficial de la compañía. ${ }^{19}$ Su vida estaba muy ligada a controlados espacios, como era el caso de los comedores. Una descripción de ello es la que entrega Gregorio Iriarte, indicando también por ejemplo que las mercaderías se vendían "sujetos al capricho del encargado de almacén, los que los suben muchas veces" solamente para buscar utilidades. ${ }^{20}$ Consecuente a las dificultades cotidianas que vivían los trabajadores bajo el régimen estanciero, sumado a las necesidades de otros gremios de trabajadores, se desarrolló la organización obrera en Magallanes, tomando impulso definitivo desde el año 1911, cuando se fundó la FOM.

Fue la primera huelga rural de carácter general de 1912 -debido al "alza de precios desmedido" que se generaba tras la instalación de la aduana en Punta Arenas- la que mostró que el poder de agencia de la organización obrera sería cada vez más significativa. ${ }^{21}$ Muestra de ello fue que a partir de 1913 se empezaron a desarrollar convenios, en los que por primera vez existieron acuerdos ramales entre los trabajadores ya fuertemente organizados y el empresariado ganadero, encontrándose ahí la administración de la SETF. Adicionalmente, todos los incidentes pasaron a ser solucionados por "un tribunal compuesto de dos estancieros y de dos obreros presidido por un quinto nombrado."22 Sin embargo, a mediados de la década de 1910, el panorama para los trabajadores se volvió aún más complejo, generándose situaciones donde se incumplían los convenios colectivos de trabajo, condicionándose la permanencia de los mismos trabajadores en sus labores a la obediencia hacia administradores, según relatan los trabajadores. ${ }^{23} \mathrm{La}$ SETF desarrolló, de esta manera, mecanismos de disciplina que daban cuenta del poder que las mismas

Postcolonial Colonialism and State Making in Patagonia. Argentina and Chile, 1840s-1922", Tesis doctoral, Stony Brook University, 2012, Pp. 155-157.

17 Descrito genéricamente en: Fernando Durán, Sociedad Explotadora de Tierra del Fuego, 1893-1943, op. cit.

18 Respecto a los administradores de la "Explotadora", el único caso que se ha investigado es el de Alexander Allan Cameron, en un trabajo que lo incluye dentro de experiencias de neozelandeses en países del Cono Sur Sudamericano: Nicholas Twohill, "The British World and its role in the relationship between New Zealand and the Southern Cone Countries of South America", Historia, No 43, Vol I, enero, junio 2010, 113-162.

${ }^{19} \mathrm{La}$ información detallada estaba en los copiadores de cuenta, donde se observa el control de salarios, venta de mercadería en los almacenes o de utensilios de trabajo a "esquiladores", además de cobros de la cuota del médico o el pago de pasajes de trabajadores que llegaban o se iban de los establecimientos. En: Archivo Instituto de la Patagonia. Copiador de Cuentas Secciones McClelland, Pousbory, Oazy Harbour, Punta Delgada. Folios 6, 7, 54, 55, 76, 99, 116 y 494.

20 Gregorio Iriarte, La Organización Obrera en Magallanes, Punta Arenas, Imprenta El Trabajo, 1915, Pp. 35-38.

21 A pesar de que aquella huelga no tuvo adhesión total del territorio. En: Alberto Harambour, "El Movimiento Obrero y la Violencia Poli $\square$ tica en el Territorio de Magallanes, 1918-1925”, Tesis para optar al grado de Licenciado en Historia. Santiago: Pontificia Universidad Cato $\square$ lica de Chile, Facultad de Historia, Geografi a y Ciencia Poli $\square$ tica, Instituto de Historia, 1999, P. 85

22 Esta práctica se mantendría se incrementaría con los años al permitirse que los obreros (mediante un "Comité") escojan representantes estancieros para participar del "Tribunal Arbitral” -órgano estatal que, como se verá, estará encargado de dirimir asuntos entre empresarios y trabajadores-, como fue lo sucedido en febrero de 1917 cuando se escogió, entre otros, a Thomas Burbury, que por esos años ya era el Administrador General de la Sociedad Explotadora de Tierra del Fuego. Información en documento con fecha 3 de Febrero de 1917: Archivo Instituto de la Patagonia. "Problemas Laborales". S/F. [Perteneciente a una carpeta sin catalogación que se ha denominado anteriormente como "Problemas Laborales": Joaquín Bascopé, "Pasajeros del Poder Propietario...", op. cit., P. 29].

23 Sobre los incumplimientos de los convenios, ver: Nicolás Gómez, "Disciplinamiento Laboral y Conflicto en Magallanes: La Sociedad Explotadora de Tierra del Fuego y los trabajadores (1893-1919)", Hernán Venegas (editor), Empresas, Empresarios y Trabajadores, Siglos XIX y XX, Santiago, Ediciones Universidad de Santiago de Chile, Departamento de Historia, 2018, P. 41-42. 
administraciones locales de los establecimientos productivos tenían, más allá de los acuerdos de mayor escala que se podían generar.

A su vez, fue fundamental el apoyo del Estado chileno -y en puntual ocasión, argentino- a administradores generales y locales, como herramienta disciplinante que sirvió en los intentos de subordinación de los obreros en los espacios de la "Explotadora". ${ }^{24}$ Primeramente, la cercanía de los gobernadores del Territorio con la administración estanciera era una de las características constantes que se podían extraer de las fuentes revisadas. ${ }^{25} \mathrm{Si}$ bien los gobernadores ejercían desde Punta Arenas virtualmente "una autoridad nominal sobre esa vastedad territorial, únicamente a través de la policía" 26 , en ocasiones se evidenciaba una acción conjunta de vigilancia. Adicionalmente, fue fundamental que la autoridad policial, representada en los "Subdelegados", fuera incluso empleada por la misma "Explotadora". ${ }^{27}$ En complemento, los "comisarios rurales ad-honorem" -autoridad policial de rango inferior y con un carácter local creada en 1907 por la Gobernación del Territorio-, fueron incluso los mismos administradores de la SETF. ${ }^{28}$ Los administradores de las estancias comenzaron así a desarrollar también una relación de mando respecto de los efectivos policiales de más bajo rango. A estos últimos se les proporcionaba desde las estancias edificios para los cuarteles, forraje y hasta los caballos para que cumpliesen con sus labores de "guardianes". 29

Tempranamente los estancieros generaron peticiones de aumento de vigilancia policial. Ya en 1896, las autoridades locales de Tierra del Fuego mencionaban la intención de los estancieros en la isla de prestar ayuda y finanzas "no tan solo a la policía, sino de hacer cuanto posible sea en beneficio de este territorio". ${ }^{30}$ Aquello se volvió más significativo cuando en 1911 las mismas autoridades de la "Explotadora" pidieron mayor eficacia y número de efectivos militares, quienes a través del llamado "Batallón Magallanes" habían iniciado sus funciones recientemente. ${ }^{31}$ De esta manera, militares y policías fueron protagonista de varios acontecimientos relacionados a la mantención del orden en los establecimientos de la SETF en la década de 1910. Si bien su relación en momentos traspasaba la

${ }^{24}$ Idea similar ya planteada en: Ernesto Bohsolavsky, El Complot Patagónico..., op. cit., P. 46.

25 Un ejemplo se encuentra en una circular del 22 de enero de 1915, donde Cameron (aún Administrador General de la compañía) indicaba a W.B. Rogers, administrador de la sección Phillip Bay ,que el gobernador Fernando Edwards visitaría la estancia, solicitando que se le facilite todo tipo de requerimientos, con fecha 22 de Enero de 1915. En: Archivo Instituto de la Patagonia. Copiador de Circulares, 1913-1918. Folio 70.

${ }_{26}$ Mateo Martinic, “El Ordenamiento Rural en Magallanes, 1894-1973...”, op. cit., P. 193

27 Aquella situación se retrata, por ejemplo, en abril de 1911, cuando en el diario "El Comercio" se anunciaba que arribaron a Puerto Bories treinta trabajadores con la promesa de un salario, "y allá se encontraron con que les pagaban menos", haciéndose la siguiente pregunta: " ¿A quién recurrir en demanda de justicia? El mismo que debía hacerla es precisamente el que cometía (...)". En la misma carta, se solicita al Gobernador de turno "en nombre de los pobladores de la apartada región de Última Esperanza" que se nombre un subdelegado "que no sea, como en la actualidad, empleado de la Sociedad Explotadora de Tierra del Fuego por no dar ninguna garantía de imparcialidad en su actuación como funcionario." En: "Solicitada", El Comercio, Punta Arenas, 03/04/1911, P. 3.

28 Sobre la situación de los "comisarios ad-honorem" se hace referencia igualmente en: Mateo Martinic, "El Ordenamiento Rural en Magallanes, 1894-1973...”, op. cit., P. 193; Alberto Harambour, "Monopolizar la violencia en una frontera colonial...”, op. cit., P. 9.

${ }^{29}$ Sobre una venta de mercadería al Comisario de Cerro Palique desde la Estancia Cerro Castillo, ver: Archivo Instituto de la Patagonia. Copiador de Cuentas Secciones McClelland, Pousbory, Oazy Harbour, Punta Delgada. Folios 123-124. Sobre una venta de caballos provenientes de Oazy Harbour en 1918, ver: Fondo Gobernación Magallanes Siglo XX, Vol. 43. Intendencia de Magallanes. Ministerio del Interior. 1908-1921. Folio 641. También hay referencia a dicho patrón cultural en: Mateo Martinic, “El Ordenamiento Rural en Magallanes, 1894-1973...”. op. cit., P. 193.

30 Carta con fecha 18 de Enero de 1896. En: Fondo Subdelegación Tierra del Fuego. Policía Tierra del Fuego, S/F.

31 Joaquín Bascopé, op. cit., P. 28. Como antecedente, en el mismo 1911, Mauricio Braun envió una carta Ministro de Guerra y Marina, con fecha 26 de enero del mismo año, solicitando mantener permanentemente en Punta Arenas a un Batallón, "que sirva para mantener el orden y a la vez garantizar la tranquilidad a los habitantes", para lo cual incluso ofrece propiedad -frente al "Club Hípico"- para que pueda instalarse definitivamente. Carta se encuentra en: Archivo Museo Regional de Magallanes. Correspondencia Mauricio Braun, Copiador 20, Folio 339. Fuente igualmente citada en: Nicolás Gómez, op. cit., P. 45. 
coordinación de acciones coercitivas en defensa de los intereses de la compañía ${ }^{32}$, fueron las huelgas lideradas por los dirigentes de la FOM la razón principal para la su intervención, durante o posteriormente a ellas.

De esta manera, los antecedentes dan cuenta de un contexto basado en un poder construido por la SETF en la cotidianeidad de sus espacios, estuvo íntimamente relacionado tanto con las atribuciones de facto de los administradores que traspasaban los acuerdos colectivos, como con el apoyo estatal que entregaron los Gobernadores y las vigilancias policiales. En dicho escenario, la violencia difícilmente pueda observarse como anomia.

\section{Violencia ganadera y estatal en la "explotadora", en la década de 1910}

Si bien la SETF debió modificar sus conductas de control mediante los "convenios" con la FOM, los administradores generaron situaciones de vejación a los trabajadores dentro de los establecimientos. La información entregada desde las fuentes representativas del mundo obrero, muestran indicios al respecto. Gregorio Iriarte hace referencia, hacia 1915, a lo humillante de un trato que, indicaba, era parte del carácter autoritario de los mandos medios y altos de la estancia de Caleta Josefina, denominada también como Bahía Inútil: “(...) no hay en ellos el tono del jefe que manda sino del amo que ordena y a quien hay que obedecer sin replicar; aprovechan todas las ocasiones que se les presentan para cometer abusos con los que están faltos de dinero, sin medios de movilización para salvar las enormes distancias que los separa del puerto vecino o de Punta Arenas." 33

Este tipo de denuncias se observaba desde 1911 en "El Trabajo". Se tendía a hacer referencia incluso al carácter de los administradores, y a la actitud que tenían frente a los obreros. Un ejemplo es el entregado sobre el "Gerente" -no indicando si se refería al Administrador General, Alexander Allan Cameron, o al mismo Mauricio Braun-, donde incluso se juzga la visión que tendría sobre los trabajadores chilenos:

La manera sistemática empleada por este señor desde la exaltación al poder de la administración de esa Sociedad merece no solo un capítulo, sino que también un libro de muchas páginas para anotar en él, no las características de su persona, pero si la índole solapada y el odio que han despertado en él los obreros del Territorio. Contándose entre las principales víctimas los nacionales, por haber en toda época tratado de defender sus derechos, rehusándose en ocasiones dejarse explotar de la manera tan rastrera como acostumbran hacerlo los jefes de sus establecimientos. ${ }^{34}$

Cuatro años después, en marzo de 1915, se denunció directamente al administrador del nuevo Frigorífico Bories, Mr Dally, quien según "El Trabajo" habría sido quien para la conmemoración del $1^{\circ}$ de mayo no permitiría que los trabajadores gocen del día libre, obligándolos a cumplir con sus labores, aunque, según se indica, varios de los obreros fueron a Natales a celebrar la "Fiesta del Trabajo". Pero además de este importante aspecto, destaca en este artículo que el señor Dally "se ha hecho para los trabajadores un bicho repulsivo" y que por la misma razón "ofrece para estos un notable contraste con su antecesor el

\footnotetext{
32 Un caso donde los militares apoyaron a la SETF más allá del resguardo del orden, se llevó a cabo en abril de 1915 cuando conscriptos del "Batallón Magallanes" realizaron una zanja en la localidad de Cerro Dorotea, lo cual según el periódico "El Trabajo", debió ser realizado por operarios de la "Explotadora". La razón era que a los conscriptos se les ofreció hacer el trabajo por dos pesos el metro, mientras que el acuerdo con los obreros era por tres, abaratando así los costos de la operación. En: "De Última Esperanza". El Trabajo ${ }_{2}$ Punta Arenas, 11/04/1915, P.1

33 Gregorio Iriarte, op. cit., P. 37. Impresión también abordada en: Joaquín Bascopé, op. cit., P. 42.

34 “El desalojo de los obreros del Territorio." El Trabajo, Punta Arenas, 26/08/1911, P. 3. La diferenciación que se hacía en la contratación de trabajadores de Chiloé era evidente en las cláusulas que se incluían y que eran condición para la mantención del puesto. Para mayor detalle sobre contratos de enganches hechos por contratistas, ver: Joaquín Bascopé, op. cit., P. 34.
} 
señor Walter L. Harries, a quien por su carácter franco y espíritu justiciero recuerdan con simpatías."35 Para los obreros, las formas de control no fueron siempre iguales en el trato, a pesar de ser dos personas que ocupaban el mismo cargo. ${ }^{36}$

Si bien los obreros denunciaban acciones violentas de parte de administradores de los establecimientos, era común encontrar referencias a acciones desde las autoridades con mayor poder de la misma empresa: gerentes o administradores generales. Además de algunas vinculadas directamente a represión que han sido relevadas en trabajos anteriores ${ }^{37}$, las acusaciones estaban dirigidas hacia el aumento de la vigilancia. Para fines de 1912, Iriarte indicaba que los delegados de la FOM, para difundir la huelga en Tierra del Fuego, debieron hacer el viaje en embarcaciones especiales, "a fin de burlar la vigilancia que la Sociedad Explotadora ejerce en Tierra del Fuego para impedir que la Federación se comunique con sus asociados." 38

La primera huelga general de las estancias magallánicas, y que incluyó paulatinamente a las de la SETF, fue entre noviembre y diciembre de 1912, aunque el origen del conflicto data desde el mes de febrero, varios meses antes de la inclusión de los trabajadores de las estancias de la "Explotadora" al conflicto. ${ }^{39}$ En el mes de diciembre se observa que los trabajadores de la sección Punta Delgada se sumaron, siendo la primera de la "Explotradora" en integrar el conflicto. Para el 9 de ese mes, la FOM afirmaba que las secciones de Bahía Inútil, Río McClelland, San Sebastián y Springhill -todas estancias y graserías de la "Explotadora"- habían adherido. ${ }^{40}$ Cortar la comunicación era, así, una de las maneras a través de las cuales, directamente, la "Explotadora" impedía el flujo de información desde los federados hacia los demás obreros de sus secciones, especialmente en instancias huelguísticas.

Otro ejemplo similar, entregado nuevamente por Iriarte, indica que para la primera huelga del frigorífico de Puerto Bories, en 1915, provocada por el despido de dos obreros. ${ }^{41}$ la "Explotadora" impidió que los obreros demuestren cuál fue el origen del conflicto, debido a que "los únicos medios de comunicación rápida es el teléfono", y la compañía "se abstiene de dar el menor dato a éste respecto." 42 Es posible corroborar, específicamente tras la mencionada huelga en 1915, que la administración de la SETF fortaleció la idea de vigilar y, consecuentemente, de cortar las comunicaciones dentro de la FOM. El 9 de marzo del mismo año, una circular firmada por Cameron (en lo que serían sus últimos mandatos) indicaba a todas las secciones que se rehúsen a reconocer a la FOM. Se agregaba que, en consecuencia, no se debían considerar ningún tipo de negociaciones con sus representantes en el campo, ni emitir cheques a nombre de la organización. ${ }^{43}$ Dicha práctica encuentra continuidad, como sucedió en marzo

\footnotetext{
35 “En Puerto Bories". El Trabajo, Punta Arenas, 16 de Mayo de 1915, P. 2

36 Igualmente se da cuenta de una posible coexistencia de heterogeneidad administrativa, necesaria de produndizar en el marco de estudio de culturas empresariales británicas en la región. Dicha idea se considera también a partir de comentarios editoriales. ${ }^{37}$ Por ejemplo, un caso ya evidenciado en trabajos anteriores, referente a un "Lamb-Marking” [marcado de ganado] en la Estancia Caleta Josefina, se evidencia que dentro de todos los aspectos a considerar, se ordena reprimir cualquier esfuerzo e interrumpir las labores: "As a rule the lamb-marking is hurried over far too quickly. Any efforts breaking must be STRONGLY REPRESSED, and in the event of rough weather(...)".Circular con fecha 1 de Octubre de 1913. En: Archivo Instituto de la Patagonia. Copiador de Circulares, 1913-1918. Folio 21; Joaquín Bascopé, op. cit., P. 32; Nicolás Gómez, op. cit., P. 45.

38 Gregorio Iriarte, op. cit., Pp. 152-153

39 Detalles sobre esta huelga en: Carlos Vega Delgado, La Masacre de la Federación Obrera de Magallanes, op. cit., Pp. 35-36; Carlos Vega Delgado, 1915 La Primera Gran Huelga Natalina, op. cit. Pp. 22-29.

40 Manuel Rodríguez, Colonos, Gañanes y Peones. Historia del trabajo y los trabajadores en Magallanes y la Patagonia, Punta Arenas, 2004 (Inédito), Pp. 398-401. URL: https://surhistoria.files.wordpress.com/2011/10/historia-del-trabajo-y-los-trabajadores-enmagallanes-y-la-patagonia-1843-1973.pdf

${ }^{41}$ Sobre una recopilación y análisis exclusivamente de esta huelga: Carlos Vega Delgado, 1915 La Primera Gran Huelga Natalina, op. cit., Pp. 43-59.

42 Gregorio Iriarte. op. cit. P. 256

43 "Please note that this office has refused to recognise the Federación Obrera in the matter of the last strike at Puerto Bories, and in consequence, you must on no account issue cheques to the order of that body, or have any dealing whatever with any of the representatives in the camp". En: Archivo Instituto de la Patagonia. Copiador de Circulares, 1913-1918. Folio 71.
} 
de 1917 cuando no se aceptó el desarrollo de la labor de un "cobrador" de la FOM.44 Ahí Burbury envió una circular desde Caleta Josefina a todas las secciones de Tierra del Fuego, avisando acerca de incidentes con el "cobrador" en la misma sección, así como en Río McClelland y Puerto Bories -ahí específicamente se hace referencia a "give a socialistic adress to workmen during the meal hour" (entrega de material "socialista" durante la hora de almuerzo)-, decidiéndose no admitir más a dicho representante. ${ }^{45}$ Se observa así una acción que bien puede representar una política de no dejar entrar a nadie que no perteneciera a las faenas y que además se considerase un potencial riesgo para la producción al adherir a ideologías como la mencionada.

La mención a la existencia de instancias patronales que diesen cuenta de acciones represivas hacia trabajadores, a lo menos es reflejo de un ambiente de tensión y de experiencias de recepción de violencia. Más específicamente, todo lo anterior, junto a las conocidas prácticas de reemplazo de la mano de obra para disuadir las mismas huelgas ${ }^{46}$, generaban un escenario donde se buscó reducir el poder de la FOM en instancias reivindicatorias, evidenciándose más frecuentemente desde 1915 en adelante. De forma similar, la SETF recurrió a otros mecanismos planificados de violencia, identificables en su vínculo con el Estado en el contexto de huelgas, o posteriormente a ellas.

A juicio de Martinic, recién en el marco de la huelga general del campo de 1916 se observó por primera vez "(...) la adopción de algunas medidas de particular rigor en resguardo del orden público en defensa de la vida y la propiedad, tipificadas en el empleo de tropa militar, hecho nunca antes constatado." 47 Sin embargo, de forma notoria, en el marco de la huelga de finales de 1912 en los primeros días de diciembre, se observó una primera acción de las fuerzas de orden, informada por "El Magallanes", zarpando a Bahía Felipe (o Phillip Bay, estancia de la SETF) el vapor "Alejandro" de la compañía Braun \& Blanchard (con capitales comunes a la "Explotadora") con un piquete de diez hombres del Regimiento "Llanquihue". ${ }^{8}$ Sobre este mismo efecto, Iriarte relataba que junto a un piquete del mismo regimiento (en este caso en la "escampavía Porvenir") iba Alexander Allan Cameron, aún Administrador General de la "Explotadora", con el objeto de "restablecer el orden en las estancias (...)."49 Iriarte entregó su propio diagnóstico sobre el conflicto de 1912:

Estimo que los estancieros no habrían tenido inconveniente en pagar lo que se les pide, pero este es el que ha producido la huelga. Había necesidad de justificar ante el Gobierno el pedido de buques y tropas para este Territorio, solicitud hecha en parte por influencia de la Sociedad Explotadora y que ha ocasionado y ocasiona al Estado una suma mayor que la que se discute actualmente. ${ }^{50}$

Más allá de encontrar solución al problema pagando lo que se solicitaba de parte de los huelguistas, se indica que lo importante era llevar tropas hasta los espacios estancieros. Esta versión coincide con las mencionadas solicitudes de aumento y mantención de tropas en el Territorio en 1896 y 1911,

\footnotetext{
${ }^{44}$ Los "cobradores" fueron quienes estaban encargados de recopilar las cuotas de la FOM. Si bien su rol no es parte del énfasis de este trabajo, es importante dar cuenta de su capacidad de difundir ideas de diversa índole dentro de los espacios productivos de la SETF. Incluso se les ha denominado “chasquis” de la Federación. Para ello, ver: Manuel Rodríguez, op. cit. Pp. $392-393$.

45 Correspondencia con fecha 2 de marzo de 1917. En: Archivo Instituto de la Patagonia. op. cit. Copiador de Circulares, 19131918. Folio 180. Fuente citada igualmente en: Joaquín Bascopé, op. cit., Pp. 40-41.

46 Ramón Arriagada relata que para una huelga general de diciembre de 1916, se entrevista a Mauricio Braun que, además de reconocer que no es posible responder a las exigencias de la FOM, explicita que tenía "el propósito de contratar obreros que quieran trabajar y hasta traerlos del norte del país, que los hay si fuera preciso.”. En: Ramón Arriagada, op. cit., P. 25.

${ }_{47}$ Mateo Martinic. Historia de la Región Magallánica, Tomo II, Punta Arenas, Ediciones Universidad de Magallanes, 2006 , P. 914.

48 "El Movimiento Obrero". El Magallanes, Punta Arenas, 9 de Diciembre de 1912, P. 7.

${ }^{49}$ Gregorio Iriarte, op. cit., P. 157.

50 Ibid. Pp.154-155
} 
confirmando la necesidad de vigilancia que tenía la "Explotadora". Al respecto, detalla Iriarte con un ejemplo, citando al diario "Chile Austral" de inicios diciembre de 1912:

Efectivamente esta vijilancia [sic] de la Explotadora no era solamente ejercida al otro lado del Estrecho sino que también en el mismo Punta Arenas, y como prueba de esto es que la tarde en que pretendían embarcarse Mancilla, Jara y [Pedro] Braun los muelles estaban vijilados [sic] por numerosa policía, teniendo que embarcarse por la playa sur, como a las 10 de la noche. ${ }^{51}$

Mayor evidencia del detalle de las acciones conjuntas, entre las autoridades de la empresa ganadera y la fuerza pública estatal, existió a comienzos del mismo año 1915, para la huelga del Frigorífico Bories, donde el gobernador Fernando Edwards tuvo especial protagonismo. Primero, ordenó detener a los obreros despedidos en un barco de la Armada, ante lo que otros trataron de rescatarlos, siendo reprimidos por la tripulación. Él mismo indicó al diario "La Unión” cuando se le consultó qué había sucedido:

Tres trabajadores a quienes se les ordenó lavaran una roldana del frigorífico se negaron a cumplir la orden. Despedidos por sus patrones declararon que no se irían y que sus compañeros se reitrarían junto con ellos del trabajo sí llegaba a cumplirse la resolución del gerente.

Llamados por mí, estos individuos declararon que no cumplirían la orden ni se retirarían del establecimiento.

Como nadie tiene derecho a vivir en casa ajena contra la voluntad de su dueño mandé a estos individuos presos a bordo del Tomé.

Agregaba, en la misma nota, haber enviado apresar a doce obreros en total, y que fue efectivo que ordenó "por escrito" hacer fuego contra cualquiera que generase atentado contra el aserradero y las maquinarias del frigorífico, y que lo volvería a hacer “(...) cuantas veces sea necesario en casos semejantes." Finalizaba el reportaje asegurando: "Todo ha quedado perfectamente tranquilo porque los elementos disolventes han sido ahuyentados o eliminados." 52

Según lo recopilado por Gregorio Iriarte respecto a este conflicto, Edwards decretó durante la huelga que: "En el término de seis horas toda persona estraña [sic] a la citada empresa o que no pertenezca al servicio público, abandonará esta región." Además, la salida de la región, además, debía ser autorizada por el "señor Capitán Bordes" o del Subdelegado de Última Esperanza, mediante salvo conducto. Se establecía la prohibición de agrupaciones de más de cinco personas y discursos que puedan derivar en exaltaciones o "mitin”. Finalmente, decretó que la autoridad “(...) castigará militar y sumariamente a los que perturben este derecho con amenazas o con actos." Al finalizar todo, se observó a Edwards volver a Punta Arenas el día 27 de febrero junto a Cameron, que ese año dejó de ser Administrador General. ${ }^{3}$ Mientras tanto, el "Batallón Magallanes" se quedó en la zona incluso después de la partida del gobernador, a pesar de que, a su llegada, el día 24 de febrero el conflicto mismo ya se había resuelto, aprensando a dos dirigentes de la FOM (Daniel Neira y Juan Vargas) en el torpedero (vapor) "Tomé" el 26 de febrero con el fin de "aislarlos del resto de los operarios y debilitar el movimiento", según se ha indicado. 54

51 Ibid. P. 155 [Se clara con los corchetes agregados que se trata de un dirigente obrero llamado Pedro Braun, para no confundir con Mauricio Braun].

52 "Reportaje al Sr. Gobernador", La Unión, 28/02/1915, P. 3. La versión indicada por Iriarte, y también considerada en otro trabajo, indica que se les encerró en el buque "Meteoro". En: Gregorio Iriarte. op. cit., Pp. 278-279; Carlos Vega Delgado, 1915 La Primera Gran Huelga Natalina, op. cit., P. 48.

53 Gregorio Iriarte, op. cit., Pp. 270-272.

54 Ramón Arriagada, op. cit., P. 18. Igualmente, el periódico "El Socialista” del 28 de febrero indicaba que, según el mismo autor, que "en Natales en esos días se respira un ambiente militarizado, ya que por todas partes hay vigilantes de uniforme". En: Idem. Días después, el 7 de marzo, indicaban que los obreros fueron "obligados a volver a sus trabajos bajo la presión de las bayonetas y de las ametralladoras de los buques surtos en el puerto." En: Kachi-Huan, "La huelga de Puerto Bories”, El Socialista, 
De estas acciones se desprende una importante función en defensa de la propiedad privada de la SETF, que cumplió la fuerza pública. Aquella práctica, según adelantan los trabajadores del periódico "El Trabajo", se comenzó a volver común posteriormente a la huelga, acusando la detención de obreros que “(...) no han cometido otro crimen que penetrar en una Estancia a conversar respecto de la huelga con los demás trabajadores. Esta fué la falta que cometieron, por esto fueron acusados de violación de domicilio." ${ }^{5}$ El panorama en 1915, después de la huelga de Puerto Bories, era tenso. La opinión pública masiva, centrada principalmente en "El Magallanes", criticó duramente la intervención del gobernador en dicho conflicto y la explicación que había dado por ella:

Acaso con los mejores propósitos de cumplir deberes que se cree inherentes al correcto desempeño de su cargo, el señor Edwards pretende avocarse el cuestionamiento de derecho privado y lo hace con tan mala suerte que provoca perturbaciones dañosas y estériles en nuestro ambiente social, precisamente en circunstancias que necesitamos paz, mucha paz, para atenuar en ella las consecuencias de una crisis dolorosa para todos. Incidentes pequeños e insignificantes como los que han ocurrido en Puerto Bories no justificaban una intervención tan enérjica [sic] y apasionada por parte de la primera autoridad administrativa del Territorio. Lo mejor en estos casos es que patrones y obreros arreglen entre ellos sus diverjencias [sic]. El entrometimiento oficioso de terceros no sirve, sino que para enredar la madeja. Las dificultades que suscitan a diario en establecimientos industriales en que se aglomeran centenares de obreros, no tienen la importancia que el aspecto trájico [sic] que le atribuye el señor Gobernador. Por lo tanto nos parece también extemporaneas las declaraciones que hizo públicas en las columnas de La Unión. ${ }^{56}$

El mismo diario mantuvo el tono de crítica a la vigilancia desarrollada posteriormente a la huelga, criticando que dos delegados de la FOM llegados a Punta Arenas, provenientes de Puerto Bories, habían sido conducidos por la policía "como grandes delincuentes": "Tratándose de dos honrados y conocidos obreros de Punta Arenas, no había para qué hacer lujo de tan aparatosa ostensión de fuerzas. Ellos solo se habrían constituido voluntariamente en la Prefectura sin necesidad de ese injustificado despliegue de guardianes.". Agrega, en relación al accionar de Edwards en este caso:

El director de la Federación [...] Muñoz se apersonó al señor Edwards a solicitar la liberación de los detenidos.

El señor Gobernador le habría respondido que permanecerían incomunicados hasta que no se restableciera el orden.

El señor Edwards habría agregado que haría tomar preso al señor Muñoz si el orden no se restablecía. ${ }^{57}$

Las acciones del gobernador Edwards hacia los trabajadores, desde la huelga de Puerto Bories, comenzaban a generar un amplio rechazo social. El día 7 de marzo del mismo año, se publicaba en "El Socialista" el resumen de unos comicios donde se expresó popularmente el rechazo al gobernador. Se hablaba de un "numeroso público simpatizante" frente a la sede de la FOM, esperando a hacer causa común en marcha junto a obreros federados. Una columna se puso en marcha, según se relata, alrededor de las diez de la mañana hasta la plaza Muñoz Gamero, donde se desarrolló una "asamblea popular". Fue el Director interino de la Federación quien abrió la sesión a través de un discurso que explicaba los motivos de la protesta, a decir según el periódico: “(...) los atropellos cometidos por el Gobernador del Territorio en la persona de honrados y pacíficos obreros, dándose el caso que en todos los puntos del

07/03/1915, P.3

55 “'Hasta cuando?”, El Trabajo, 30/05/1915, P. 1.

56“Intervención inoportuna”, El Magallanes, 02/03/1915, P. 7.

57 "La llegada de los delegados de la Federación Obrera. Nuestra censura”, El Magallanes, 03/03/1915, P. 7 
territorio donde éste funcionario estuvo en visita de inspección había dejado víctimas obreras, maldiciéndolo como hombre inhumano y como funcionario déspota." Se llegó al acuerdo, "unánimemente", de protestar ante el Presidente de la República frente a la actitud de Edwards, solicitar garantías individuales ante su desconocimiento frente al "provecho y defensa de los intereses de la Soc. Explotadora", y elevar una solicitud pidiendo la destitución del gobernador. ${ }^{58}$

La crítica de "El Socialista" continuaba, refiriéndose a Edwards como aquel que había quebrado una armonía que "más o menos" se desarrollaba entre una clase y otra, debido al "(...) temor de los capitalistas que temían que los obreros representados por la Federación se extralimitasen en sus exijencias [sic] (...)." Se describía, al gobernador, en la respectiva columna como: “(...) un Señor de muchos bríos (para con los humildes) y les dio a entender que eso de tratar de potencia a potencia con los trabajadores era indigno, que no había porque pactar con ellos condiciones sino imponérselas con mano de hierro y que él se encargaría de aplastarlos bajo su planta, porque son seres desprovistos de toda[o] derecho (!)". Se indica en la misma noticia que el Edwards declaró para la huelga de Puerto Bories que "la Federación Obrera era una serpiente á quien tenía pisada la cola y que en breve le aplastaría la cabeza"'. Finalmente, dando cuenta de un panorama de disputa de poder y tenso, se declara: "El guante ha sido lanzado; lo recogeremos cuando lo creamos oportuno y entonces veremos quién pierde más, si nosotros los que nada tenemos y que todo lo producimos, ó ellos, los que cada minuto de paralización en sus industrias se traduce en un montón de libras esterlinas que pierden". ${ }^{59}$

Más allá de lo expresado por la opinión pública sobre el proceder del gobernador y los desafíos que planteaba para los obreros organizados, en una carta con fecha 20 de abril de 1915 el mismo gobernador Edwards redactó al Ministerio del Interior solicitando aumentar la dotación policial regional. Como se ha observado, aquella no es la primera acción de dicha connotación registrada desde el Territorio o en relación con la SETF, explicando en este caso cómo la creación del Frigorífico Bories les planteó la necesidad de más tropas, debido al escaso personal de la prefectura que resguardaba en Puerto Natales (46 guardianes). Entregó así un listado con todo lo necesario para fortalecer la vigilancia, explicaba: "Teniendo la Prefectura un número de tropa montada indispensable, puede asegurar en cualquier momento de tumultos, huelgas o desórdenes, el resguardo de los intereses jenerales [sic] de los estancieros, comerciantes e industriales." Indicaba Edwards en la misma carta:

Desde que me hice cargo de la Gobernación de Magallanes, en todos mis informes enviados al Supremo Gobierno, con motivo de las últimas huelgas habidas en el Territorio, he solicitado aumento de fuerza policial como medida indispensable para mantener el orden, y evitar estas conmociones periódicas del elemento obrero que en Magallanes se suceden sin interrupción y sin motivo alguno, con grave perjuicio para las industrias del Territorio. ${ }^{60}$

Si bien la inclusión de las fuerzas de orden en el control de la mano de obra era un proceso continuo, la incidencia del gobernador Fernando Edwards pudo establecer un punto de recrudecimiento en las acciones de violencia estatales en coordinación con la SETF, según se puede constatar en la importante cantidad de evidencia existente para los primeros meses de 1915. Esto incluso avalado por una carta de todos los estancieros al diario nacional El Mercurio, donde se aludía al peligro de anarquistas y ex

58 "El Comicio del Domingo", El Socialista, 07/03/1915, P. 1

59 Kachi-Huan, "Momentos de prueba", 21/03/1915. El Socialista, P. 2-3.

60 Además, indicaba al territorio de Magallanes como un "punto obligado de refujio" de ex presidiarios de Ushuaia (Argentina), "y de elementos perniciosos fugados de todas partes de Europa.". En: Gobernación de Magallanes a Ministerio del Interior, 20 de Abril de 1915. En: Fondo Gobernación Magallanes Siglo XX, Vol. 20. Intendencia de Magallanes. Folios 248-251. 
presidiarios de Ushuaia, pero donde "El Socialista" acusaba que era solamente una estrategia para, entre otras cosas, "obligar a los trabajadores a aceptar el mísero salario que a ellos les convenga pagar." 61

Hacia 1916, en documentación oficial del Estado de Chile, se continuaba dando cuenta de aumentos de dotación policial en Última Esperanza al servicio de los intereses estancieros, especialmente de la "Explotadora". En una carta enviada en 29 de septiembre de dicho año, el Director del Cuerpo de Carabineros del Ministerio del Interior indicaba a la Gobernación de Magallanes, que una tropa del "Escudrón Puerto Montt" quedaba "a las órdenes" de dicha compañía. ${ }^{62}$ Consecuentemente, un mes después, se acusaba en el mismo "El Socialista" la llegada de diez carabineros y un oficial63, así como en noviembre del mismo año se acusaba la instalación en Puerto Bories de un mayor refuerzo policial de forma permanente, según uns carta emitida con fecha 30 de octubre de 1916, indicando que la "Explotadora" convirtió al establecimiento en un "verdadero cuartel". Se agregaba en dicha carta: "La Explotadora tiene a su servicio el piquete de carabineros recientemente llegado a esta región. En la puerta del Frigorífico hay apostados dos carabineros y adentro, donde se saca la ficha, otros dos. (..) ¡Por algo el Presidente de la República es accionista! (...)" ${ }^{64}$ Parece ser coherente la concatenación de hechos desde la solicitud de estancieros acusada por los periódicos obreros, y el arribo de nueva dotación vigilante y represiva al territorio. Interesante es, a la vez, la alusión al Presidente de Chile, abriendo preguntas más amplias respecto a las ingerencias de otras autoridades estatales, incluidas quienes estaban en el poder central.

Última Esperanza se había convertido, quizás, en la región más vigilada -desde 1916, "dos grupos de carabineros estaban destacados bajo dependencia del Escuadrón Puerto Montt", repartidos entre Cerro Castillo y Puerto Bories ${ }^{65}$ y con más episodios de agresión por parte de autoridades hacia los obreros. Ejemplo de ello fue lo sucedido en Cerro Castillo, estancia conocida a través de investigaciones anteriores por el asesinato del obrero Pedro Alvarado, mediante azotes por parte de la policía de la estancia en 1917. Pero también en la carta enviada por obreros al Presidente de la República de Chile, se denunciaban también torturas, "con motivo de una mera sospecha de hurto", en el Cuartel de Carabineros de Puerto Natales. ${ }^{66}$ Y, en ese mismo espacio y prácticamete un año antes del asesinato de Alvarado, en noviembre de 1916, se acusaban "abusos de carabineros" contra los obreros, describiendo la misma práctica: poner en "la barra" y golpear a un hombre, en este caso al obrero Eduardo Frías. Presumiblemente, según se indica en la fuente, por ser parte de la FOM, tras un allanamiento a su residencia. Además se describen otros abusos en contra de obreros de apellido Díaz, Rodríguez y Valenzuela. ${ }^{67}$ No fue el caso del obrero Alvarado, entonces, un hecho aislado, siendo pertinente preguntarse respecto a la sistematicidad de los azotes como mecanismo de disciplinamiento y castigo en la "Explotadora".

El culpable, a juicio de varios medios de la época, era principalmente el Administardor de Cerro Castillo, Mr. Maltzan, siendo sus acciones fueron reportadas incluso hasta 1918. El día 31 de enero de aquel año, se publicaba una columna también en "El Socialista" donde se acusaba la existencia de "(...) numerosas las quejas que se publican contra la sección de la Explotadora de Cerro Castillo (...)." La crítica iba directamente a Maltzan de la estancia, a quien se le sindicaba como quien mandató a los carabineros

61 "Cae la careta", El Socialista. 24/06/1915. P.1. En "El Trabajo" se hace acusación de la misma situación en: "La Garra del Felino”, El Trabajo. 20/06/1915, P. 1

${ }^{62}$ Fondo Gobernación Magallanes Siglo XX, Vol. 43. Intendencia de Magallanes. Ministerio del Interior. 1908-1921, Folio 261.

63 “Carabineros para UE", El Socialista, Punta Arenas, 12/10/1916, P.1.

${ }^{64}$ E.A.V, "La Explotadora provoca a los trabajadores por medio de los carabineros", El Socialista, 09/11/1916, P.1.

65 Alberto Harambour, "El Movimiento Obrero y la Violencia Poli $\square$ tica en el Territorio de Magallanes, 1918-1925”, op. cit., P. 101.

${ }^{66}$ Fondo Gobernación Magallanes Siglo XX, Vol. 43. Intendencia de Magallanes. Ministerio del Interior. 1908-1921, Folio 472. Específicamente el asesinato de Pedro Alvarado se denunció inicialmente en la prensa: "Un asesinato bárbaro". El Socialista, Punta Arenas, 28/09/1917. P.1. Este episodio es igualmente relatado en: Ramón Arriagada, op. cit., P. 14.

67 "Abusos de los carabineros contra los obreros de Cerro Castillo", El Socialista, Punta Arenas, 16/11/1916, P.2. 
que “(...) ultimaron a un honrado obrero [probablemente refiriéndose al mismo caso de Alvarado], poco después fueron injustamente despedidos gran número de obreros (...)." También la crítica iba hacia el Administrador General de la SETF, T.R.D. Burbury, a quien se solicitaba que cumpla con sus “(...) promesas hechas de siempre obrar con justicia(...)", existiendo a juicio de los acusantes "(...) suficientes pruebas para proceder eliminando la causa principal de las quejas de Castillo: el señor Maltzan." 68 La resumida columna complementaba una noticia aparecida en "El Magallanes" dos días antes, en la cual se describía la última situación acaecida el día 15 de enero del mismo año, donde un capataz de la estancia habría insultado ("apostrofó") a un "(...) muchacho ocupado en la faena (...)", y Maltzan explulsó a quienes " $(. .$.$) protestaron y quisieron pedir justicia (...)", según indicaba un trabajador. { }^{9}$

El año 1916 finalizó con una nueva huelga, en este caso de carácter general. En diciembre, los trabajadores del campo -entre los cuales estaban los pertenecientes a la "Explotadora"- realizaron una "marcha" desde Puerto Natales a Punta Arenas, algunos a caballo, a pie o en carros, llegando el día 11 de diciembre a destino. La razón de la huelga fue un desacuerdo de la FOM con los ganaderos del territorio para las faenas de esquila venideras, que unánimemente decían: "es muy alta la pedida de los trabajadores". ${ }^{70}$ Fue en el contexto de esta huelga que se conformó el "Comité de Estancieros", que integraba también el entonces nuevo Administrador General de la SETF, Thomas Burbury. ${ }^{71}$ Todas las estancias de Tierra del Fuego en Chile y Argentina se unieron a una huelga que se llevó a cabo con la mayor de las tranquilidades. ${ }^{72}$ Sin embargo, el diario "El Magallanes" del 9 de diciembre de 1916 entrevista al delegado de la FOM que regresaba desde Puerto Natales a Punta Arenas, quien manifestaba en torno a provocaciones que Carabineros generaban a los huelguistas, impidiendo incluso "que los huelguistas sacaran sus ropas" de Puerto Bories. ${ }^{73}$ Coherente con acciones como las indicadas, es "El Socialista" indicaba en relación a la resistencia de los huelguistas: "No han sido suficientes ni las amenazas de una intervención armada, ni la de represalias patronales, (...) a quebrantar su admirable entereza de luchadores". ${ }^{74}$

La intimidación de la policía en esta ocasión fue severa, llegando incluso uno de los obreros a portar declaraciones escritas y un parte médico que constataba lesiones provocadas por efectivos. Y luego, como anteriormente, se hizo presente el "Batallón Magallanes" saliendo "en dirección a estancias vecinas, con el propósito de resguardar el orden" 75 . Y si bien la huelga tuvo una solución, esta se llevó a cabo mediante la intervención de la Junta de Alcaldes de Magallanes, y con la constitución de un "Tribunal Arbitral", "encargado de resolver las dificultades que podían ocurrir entre patrones y obreros". ${ }^{76}$ Coherentemente, según se constata en circular enviada por Thomas Burbury el 15 de febrero de 1917 a todas las secciones, se llegó a acuerdo mediante Acta Municipal para que los inspectores municipales puedan observar las condiciones de los asentamientos tras la huelga. Aquello se decidió bajo condiciones favorables para la SETF, indicando Burbury que se entreguen las facilidades al inspector, habiendo sido designado para tales albores el señor Pablo Karaman, hombre de confianza de la compañía y contratista encargado de obreros para la SETF. ${ }^{77}$

El carácter vigilante y violento del mundo ganadero se vio reforzado tras la huelga, según se siguió constatando. En 1917, "El Socialista" acusaba la presencia constante de militares de noche y

\footnotetext{
68 "Incorrecciones de una estancia", El Socialista, 31/01/1918, P. 1.

69 "Correcciones en una estancia", El Magallanes, 29/01/1918. P. 7.

${ }^{70}$ Ramón Arriagada, op. cit., P. 25.

71 Según indica Arriagada, el comité iba a estar compuesto por: Alejandro Menéndez Behety (hijo de José Menéndez), Francisco Campos Torreblanca, Thomas Burbury y Mauricio Braun, los dos últimos ligados a la Sociedad Explotadora de Tierra del Fuego. En: Ibid. P. 37

72 "La Cuestión Obrera", El Magallanes, 05/12/1916, P. 3. Información relatada también en: Ramón Arriagada, op. cit., P. 26.

73 Ibid. Pp. 26-29.

74 "La huelga continúa", El Socialista. 21/12/1916, P.1.

${ }^{75}$ Carlos Vega Delgado. La Masacre de la Federación Obrera de Magallanes, op. cit., P. 65.

76 Ramón Arriagada, op. cit., P. 35.

77 Archivo Instituto de la Patagonia. Copiador Circulares 1913-1918. Folio 176.
} 
policías de día con rifles, en resguardo de la casa de Thomas Burbury. ${ }^{78}$ Incluso, en el mismo año, un empoderado "Comité de Estancieros" presionó para nombrar al militar Luis Contreras Sotomayor en la Gobernación del Territorio de Magallanes. De su parte, se evidenció su claro apoyo a los intereses de la "Explotadora", respondiendo a las peticiones de los estancieros. Por ejemplo, nuevamente en "El Socialista", el 31 de enero de 1918 se escribió una columna titulada "Estemos preparados" donde se indicaba el desconocimiento por parte de la SETF de los acuerdos con la FOM, contando con el apoyo de Contreras. ${ }^{79}$ De manera coherente, en octubre del mismo año, se indicaba en el diario "El Magallanes" que el nuevo gobernador intervino directamente para solucionar diferencias entre obreros y patrones, designando él mismo los cobradores de la Federación Obrera, y emprendiendo un viaje a las estancias a fin de solucionar cualquiera duda o diferencia que se presentase, acompañado por el Administrador General, Thomas Burbury. ${ }^{80}$ De esa manera, el panorama estaba lo suficientemente tensionado y preparado para episodios más complejos aún de lo que ya se estaban generando, como fueron los "Sucesos de Natales" de comienzos de 1919.

\section{Conclusión}

La información entregada, tanto en este como en citados trabajos, permite obtener (re)observar multidimensionalmente el ejercicio de la violencia concertada desde la SETF, y con la participación del Estado, anteriormente a la represión ejercida en la emblemática huelga de Puerto Bories de 1919. Es posible esclarecer una sistematicidad del ejercicio de la violencia empresarial que se desarrolló principalmente a partir de las huelgas de 1912, 1915 y 1916, pero no exclusivamente en dichos contextos, generándose un escenario de vigilancia, "malos tratos", castigo y represión en contextos de huelgas que, por momentos, según se expresaba desde los medios obreros, se tornaba tenso. Se constata, de esta manera, la construcción de escenarios de luchas de poder donde los administradores ganaderos poseían el ejercicio de la violencia, directa o delegada, como recurso de control.

Tal como la FOM desde la reivindicación de derechos laborales, los administradores de la "Explotadora", mayoritariamente, fueron confrontacionales en la búsqueda de la mantención de las cuotas de poder que les permitiesen conservar el control de la producción mediante la disciplina obrera. La violencia ejercida se basó, a juicio de quien escribe, en una triple lógica: fue política en tanto que se legitima desde el Estado; fue económica en tanto que es parte de la mantención de un modelo basado en el liberalismo desregulado y monopólico comandado por oligarquías ganaderas y mandos medios con importantes privilegios (los administradores); y, por tanto, fue social en tanto que se conformó una la elite local que la ejerció o propició contra una (aunque heterogénea) clase social subordinada. Esto último, especialmente, es lo que les entrega un carácter "patronal" clasista al ejercicio de las violencias analizadas.

Cabe señalar que este trabajó ha intentado responder a la necesidad de aportar en el diálogo respecto a una época desde la cual ya ha pasado un siglo. A cien años del desarrollo de estos acontecimientos, es innegable considerando un "boom" de la memoria histórica y de preguntas referentes al cómo se recuerda o representa el pasado en Magallanes, especialmente cuando da cuenta de violencias que, como se indicó, han sido vistos por algunas interpretaciones como anomias o tragedia específicas en un panorama de progreso. Es así como se ha buscado contribuir en el resalto de una crítica al comportamiento de conformadas elites económicas y políticas regionales de comienzos del siglo XX, evidenciando su incidencia en un panorama de conflicto constante y no solamente episódico.

Mayores especificidades y ribetes que se puedan extraer de la presente contribución, deberán ser cubiertas en próximas publicaciones. Si bien en el presente trabajo se ha estudiado el caso específico de

\footnotetext{
78 "Resguardando la propiedad", El Socialista, Punta Arenas, 18/01/1917, P.2

79 "Estemos preparados", El Socialista, Punta Arenas, 03/01/1918, P.1.

80 "De actualidad. El convenio obrero. Próximo a ser formado. Principales cláusulas. Otras informaciones". El Magallanes, Punta Arenas, 24 de Octubre de 1918, P. 7.
} 
la "Explotadora" - debido a la significancia del caso por las razones retratadas anteriormente-, se hace necesario en el futuro ampliar el estudio del ejercicio de la violencia a nivel de toda la ganadería magallánica. ¿Puede hablarse de una cultura de la violencia en las prácticas disciplinantes de la mano de obra en la ganadería, o solamente es posible remitirse a la coexistencia de particularidades? ¿Puede aquella violencia extenderse más allá de elementos evidentes de conflictividad, y abordar aspectos ligados a patrones culturales subyacentes, como la diferenciación étnica, considerando el origen europeo de gran cantidad de los administradores ganaderos? Sin dudas, son preguntas que desafían a profundizar la historia empresarial y de las relaciones laborales en la región.

\section{BIBLIOGRAFÍA:}

Ramón Arriagada, La Rebelión de los Tirapiedras, Punta Arenas, Ediciones Universidad de Magallanes, 2010.

Joaquín Bascopé, "Pasajeros del Poder Propietario. La Sociedad Explotadora Tierra del Fuego y la Biopolítica Estanciera (1890-1920)", Magallania ,Vol 36, 2008, 19-44.

Ernesto Bohoslavsky, El Complot Patagónico: Nación, Conspiracionismo y Violencia en el sur de Argentina y Chile, Siglos XIX y XX, Buenos Aires, Prometeo Editorial, 2009.

Jorge Corsi y Graciela Peyrú, Violencias Sociales, Buenos Aires, Ariel, 2003.

Jean Paul De Gaudemar, El Orden y la Producción. Nacimiento y formas de disciplina en las fábricas, Madrid, Edtorial Trotta, 1991.

Fernando Durán, Sociedad Explotadora de Tierra del Fuego, 1893-1943, Santiago, Imprenta y Litografía Universo, 1943.

Nicolás Gómez, "Disciplinamiento Laboral y Conflicto en Magallanes: La Sociedad Explotadora de Tierra del Fuego y los trabajadores (1893-1919)", Hernán Venegas (editor), Empresas, Empresarios y Trabajadores, Siglos XIX y XX, Santiago, Ediciones Universidad de Santiago de Chile, Departamento de Historia, 2018, 17-54.

Eduardo González Calleja, La violencia en la poli $\square$ tica. Perspectivas teo $\square$ ricas sobre el empleo deliberado de la fuerza en los conflictos de poder, Madrid, Consejo Superior de Investigaciones Cienti $\square$ ficas (CSIC), 2002, P. 61.

Adriana González Gil, "Acción colectiva en contextos de violencia prolongada", Estudios Políticos, Medellín, No29, julio-diciembre 2006, P. 37.

Alberto Harambour, "Borderland Sovereignties. Postcolonial Colonialism and State Making in Patagonia. Argentina and Chile, 1840s-1922”, Tesis doctoral, Stony Brook University, 2012

"El Movimiento Obrero y la Violencia Poli $\square$ tica en el Territorio de Magallanes, 1918-1925”, Tesis para optar al grado de Licenciado en Historia. Santiago: Pontificia Universidad Cato $\square$ lica de Chile, Facultad de Historia, Geografi $\square$ a y Ciencia Poli $\square$ tica, Instituto de Historia, 1999.

"Monopolizar la violencia en una frontera colonial. Polici $\square$ as y militares en Patagonia austral (Argentina y Chile, 1870-1922)", Quinto Sol, Vol. 20, No 1, enero-abril 2016, 1-27. 
"Sheep Sovereignties: The Colonization of the Falkland Islands/Malvinas, Patagonia, and Tierra del Fuego, 1830s-1910s", Oxford Research Encyclopedia of Latin American History, sept 2016, 1-25.

,"Soberanía y Corrupción. La construcción del Estado y la propiedad en Patagonia austral", Historia, No 50, Vol II, julio-diciembre 2017, 555-596.

Gregorio Iriarte, La Organización Obrera en Magallanes, Punta Arenas, Imprenta El Trabajo, 1915.

Tomás Mantecón, "Formas de Disciplinamiento Social. Perspectivas históricas", Revista de Historia Social $y$ de las Mentalidades, Vol 14, N², 2010

Mateo Martinic, "El Ordenamiento Rural en Magallanes, 1894-1973: La dirección y el manejo de las grandes estancias", Vida Rural en Chile Durante el Siglo XIX, Santiago, Academia Chilena de la Historia, 2001.

Magallanes, 2006

, Historia de la Región Magallánica, Tomo II, Punta Arenas, Ediciones Universidad de , "Recordando a un Imperio Pastoril: La Sociedad Explotadora Tierra del Fuego (18931973)", Magallania, Vol. 39(1), 2011, 5-32.

Oscar Peñafiel, "Violencia patronal, mayordomos, policías: Paternalismo patriarcal en la cuenca carbonífera. Lota, 1910-1920”, Revista Tiempo Histórico, Año 6, Nº11, julio-diciembre 2015.

Manuel Rodríguez, Colonos, Gañanes y Peones. Historia del trabajo y los trabajadores en Magallanes y la Patagonia, Punta Arenas, 2004 (Inédito). URL: https://surhistoria.files.wordpress.com/2011/10/historia-deltrabajo-y-los-trabajadores-en-magallanes-y-la-patagonia-1843-1973.pdf

Nicholas Twohill, "The British World and its role in the relationship between New Zealand and the Southern Cone Countries of South America", Historia, No 43, Vol I, enero, junio 2010, 113-162.

Carlos Vega Delgado, 1915 La Primera Gran Huelga Natalina, Punta Arenas, Impresos Ateli, 2009.

Edición, 2002. , La Masacre de la Federación Obrera de Magallanes, Punta Arenas, Editorial Ateli, $2^{\circ}$

\section{Prensa}

El Magallanes, Punta Arenas, Chile. 1894-.

El Socialista, Punta Arenas, Chile. 1913-1950.

El Trabajo, Punta Arenas, Chile. 1911-1926. 


\section{Fuentes primarias}

Archivo Instituto de la Patagonia (Punta Arenas, Chile): Copiadores de carta y de cuentas Sociedad Explotadora de Tierra del Fuego. Disponibles en: http://www.bibliotecadigital.umag.cl

Archivo Museo Regional de Magallanes (Punta Arenas, Chile): Correspondencias Mauricio Braun.

Archivo Nacional Histórico (Santiago, Chile): Fondo Gobernación Magallanes. 